\title{
Isolation and Molecular Identification of Potential Probiotic Yeast Strains Found in Malaysian Kefir Drinks Samples
}

\author{
Mohd Akmal Azhar and Mimi Sakinah Abdul Munaim \\ Faculty of Engineering Technology, Universiti Malaysia Pahang, Kuantan, Malaysia \\ Email: \{akmalba, mimi\}@ump.edu.my
}

\begin{abstract}
Kefir drink is a product from the fermentation process of milk using symbiotic mixture of bacteria and yeast consortium. Saccharomyces and lactobacillus are the major genera found in the kefir drink. The present work involves the isolation and identification of potential probiotic yeast strains in the kefir drink samples from Malaysia. The molecular identification was done by PCR using ITS1 and ITS4 amplified regions. Nine different yeast strains were isolated, and the strains were successfully identified based on the sequence analysis. Saccharomyces and Kodamaea were found to be the major population in the kefir drink samples. Lastly, kefir milk is one of the excellent sources of probiotic yeast strains and could be used as a new yeast probiotic formulation or in food supplements. Moreover, the amplification of ITS region can be used as a useful method to identified yeast strains.
\end{abstract}

Index Terms-kefir, yeast, probiotics, molecular identification, PCR

\section{INTRODUCTION}

Kefir drink is a product that undergoes a fermentation process using milk as a medium. The taste is quite acidic and it has a creamy-like texture [1]. It is normally produced from a traditional kefir grains or kefir starter cultures by fermentation process. Kefir comprises a microbial symbiotic mixture of bacteria and yeast that attached to a polysaccharide matrix [2]. Although the bacterial population is dominant in kefir, the presence of yeast plays an important role to develop the flavour as well as chemical composition of the kefir product. Moreover, the yeast strains are important for the microbial balance by providing the essential nutrients for a probiotic bacteria population such as vitamins and amino acid and produce some compounds that contribute to the kefir drink taste [3].

Based on a previous report, majority of the bacterial and yeast strains that can be found in the kefir drink are Lactobacillus and Saccharomyces [4] that are recognised as probiotic microorganisms. The term probiotics originates from the Greek word 'probios', which stands 'for life', but the latest definition by FAO/WHO describes them as "live microorganisms which when administered in adequate amounts confer a health benefit on the host" [5].

Manuscript received February 16, 2019; revised August 12, 2019.
In the recent years, the use of a probiotic product containing beneficial strain is not only for gastrointestinal disease treatment but also for the overall human health in medicine and dentistry. A considerable amount of literature has been published on the therapeutic potential and health benefit of probiotics such as the prevention of diarrheal disease [6], colon cancer [7], and upper GI tract disease [8], and to improve the immune system against intestinal infections [9].

In the nutraceutical industry, most of the probiotic products contain lactic acid bacterial strains. Yeast strains have been also reported to have the probiotic ability. However, a very few reports regarding probiotic from yeast is available compared to that from bacterial strains although it has a good potential of probiotic ability that can benefit the human health. Compared to the probiotic bacterial strains, products containing yeast are not as widely available but are fast developing and becoming more common. Therefore, the purpose of this research is to isolate, classify and sellect the predominant probiotic yeast from the Malaysian kefir drink using molecular identification technique through PCR method for potential probiotic attrubutes.

\section{MAterial AND Methods}

\section{A. Isolation of Yeast from Kefir}

The yeast samples used for this work were isolated from a kefir drink bought from a supplier in Gambang, Pahang, Malaysia. The samples were kept chilled at $4{ }^{\circ} \mathrm{C}$ in the sterile bottle until further use. The isolation process was done using standard serial dilution technique and spread over Yeast Extract Peptone Dextrose (YEPD) agar for $48 \mathrm{~h}$ at $30{ }^{\circ} \mathrm{C}$. After incubation, yeast colonies were selected and streaked again on YEPD agar plates for purification. The grown single colonies were stored at $4{ }^{\circ} \mathrm{C}$ for further study.

\section{B. DNA Isolation}

The isolated yeasts strains were cultured on Yeast Extract Peptone Dextrose (YEPD) broth for $24 \mathrm{~h}$ at $30{ }^{\circ} \mathrm{C}$ The yeast strains were treated with $10 \mathrm{mg} / \mathrm{mL}$ of proteinase $\mathrm{K}$ and $2.5 \mathrm{mg} / \mathrm{mL}$ of lyticase followed by genomic DNA extraction using GFX Genomic Blood DNA Purification Kit (Amersham Biosciences, UK) using the protocol provided. The PCR products were run 
on $1 \%(\mathrm{w} / \mathrm{v})$ agarose gel, stained with GelRed $\AA$, and visualised under ultraviolet light transilluminator.

\section{PCR Analysis}

Polymerase Chain Reaction (PCR) was carried out using universal primers named ITS1 and ITS4. The reaction was carried out in $0.2 \mathrm{~mL}$ PCR tubes in $25 \mu \mathrm{L}$ reaction mixture containing purified genomic DNA, PCR buffer, 1 unit of Taq polymerase, forward and reverse primers, and dNTPs. The reaction was carried out for 30 cycles under the following condition: 2 min of initial denaturation at $98{ }^{\circ} \mathrm{C}$ followed by the PCR cycle consisting of denaturation at $98{ }^{\circ} \mathrm{C}$ for $15 \mathrm{~s}$, annealing temperature at $60{ }^{\circ} \mathrm{C}$ for $30 \mathrm{~s}$, and extension at $72{ }^{\circ} \mathrm{C}$ for 30 s. The PCR cycles were followed by an additional final extension at $72{ }^{\circ} \mathrm{C}$ for $10 \mathrm{~min}$. The PCR products were run on $1 \%(\mathrm{w} / \mathrm{v})$ agarose gel, stained with GelRed ${ }^{\circledR}$, and visualised under ultraviolet light transilluminator.

\section{Gene Sequencing and Identification}

The PCR products were gel-purified and cloned into pJET1.2 according to the manufacturer's protocol (Thermo Fisher Scientific). The plasmids of nine positive clones were purified and sequenced with 1st BASE universal primer LpJET1.2F using BigDye ${ }^{\circledR}$ Terminator v3.1 Cycle Sequencing Kit (Applied Biosystems) by 1st Base Sequencing services (Selangor, Malaysia). The bioinformatics analysis of the sequencing results was performed using the basic local alignment search tool (BLAST). The identification at the taxonomic level of species were allowed between $99 \%$ and $100 \%$.

\section{RESUlTS AND DISCUSSIONS}

\section{A. DNA Isolation}

In the present study, all the isolated yeast strains were treated with lyticase and proteinase $\mathrm{K}$ before proceeding with the genomic extraction protocol. Proteinase $\mathrm{K}$ is often used during the extraction of DNA to digest protein and remove contamination from the preparation of nucleic acid. It acts as a serine protease that cleaves the peptide bond adjacent to the carboxyl group of aliphatic and aromatic amino acids with blocked alpha amino groups [10]. The major component of the yeast cell wall contains mannoprotein, chitin, $\beta-(1 \rightarrow 6)-D-g l u c a n$, and $\beta-(1 \rightarrow 3)$-D-glucan. One of the obstacles in the yeast genomic DNA recovery is the disruption of the cell wall. Therefore, lyticase was used to lyse $\beta-(1 \rightarrow 3)$-D-glucan in the yeast cell wall structure [11]. The extracted chromosomal DNA (Fig. 1) from the isolated yeasts were purified and dissolved in deionised water and stored at $-20{ }^{\circ} \mathrm{C}$

The genomic DNA from the potential probiotic yeast strains were successfully isolated and visualised on the agarose gel electrophoresis. A single band obtained indicates that the isolated genomic DNA was not degraded and stayed intact - the genes were isolated in good quality. Moreover, the band located above the $10 \mathrm{~kb}$ ladder proves that it was chromosomal genomic based on the larger sized observed [12].

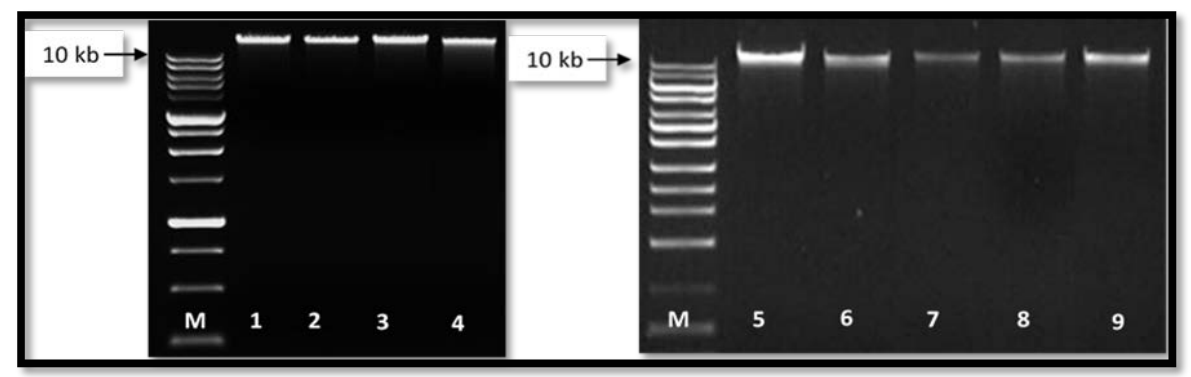

Figure 1. Electrophoresis separation of genomic DNA fragments from the isolated yeast strains. Lane M: 1 kb ladder (Promega); Lanes 1-9: isolated yeast genomic DNA.
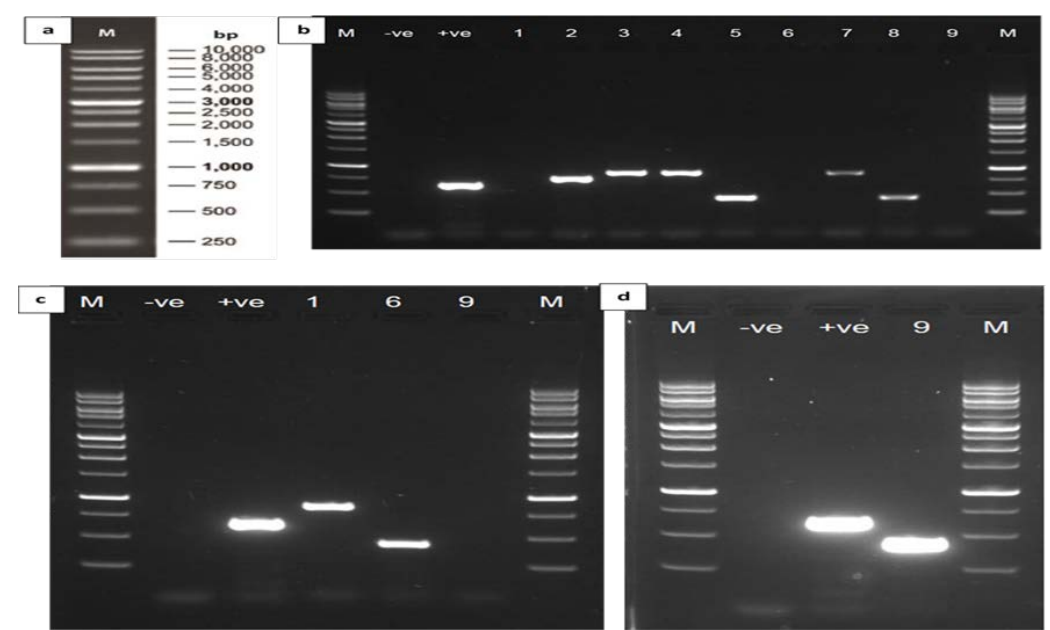

Figure 2. PCR amplification of ITS region for all isolated yeast strains. Lane M: 1 kb ladder; Lanes 1-9: fragment of ITS region for all isolated yeast. 


\section{B. PCR Analysis}

The genes of the isolated yeast strains were successfully amplified using the universal primers internal transcribed spacers (ITS), ITS1 and ITS4. The resulting amplicons are shown in Fig. 2. The DNA ladder as a control size for all gel separation is shown in Fig 2a while Fig 2b-d shows nine amplicons from different samples. Single bands of PCR amplification were obtained between 300 and 800 bp. These results are consistent with the data obtained from a previous study where the normal ITS amplicon size for yeast size ranged from 300 to 900 bp depending on the type of species [13].

Internal transcribed spacer (ITS) refers to the spacer DNA situated between the small-subunit ribosomal RNA (rRNA) and large-subunit rRNA genes in the chromosome. It contains two noncoding spacer regions between 18s and 28s including 5.8s rRNA gene [14]. In yeast and fungal species, the universal primers ITS1 and ITS4 are commonly used to amplify the region. In fungal and yeast species, the PCR amplified ITS region will be highly important to differentiate the strains species [15]. The polymorphism distance between ITS1-ITS4 region among the species was in the range of 400 and 800 bp and can be detected in the PCR products (Fig. 2).
From the result, lanes $1,3,4$, and 7 have the longest amplified sequence around $800 \mathrm{bp}$. On the other hand, lanes 5, 6, 8, and 9 show the shortest sequence around 400 bp. The similarity in sequence length indicates that they might be in the same genus or species with small variation of strain.

\section{Gene Sequencing and Identification}

All the purified PCR fragments were ligated into pJET1.2 vector (Thermo Fisher) and then transformed into E. coli strain JM109. pJET1.2 vector is the cloning system generated with Pfu DNA polymerase, Taq DNA polymerase, or another thermostable DNA polymerase with blunt or sticky ends. A successful cloning of insert into the pJET1.2 vector was identified by growing the colonies on LB-ampicillin agar plates. The positive recombinant plasmids were sequenced using universal primer LpJET1.2F by 1st Base Laboratories (M) Sdn. Bhd., Malaysia.

The determined nucleotide sequences of the amplified fragments were subjected to search against all known sequences in database (BLAST search). The yeast species similarity was determined based on the highest bit score and identified percentage from the hit BLAST from the National Centre for Biotechnology Information (NCBI) as shown in Fig. 3.

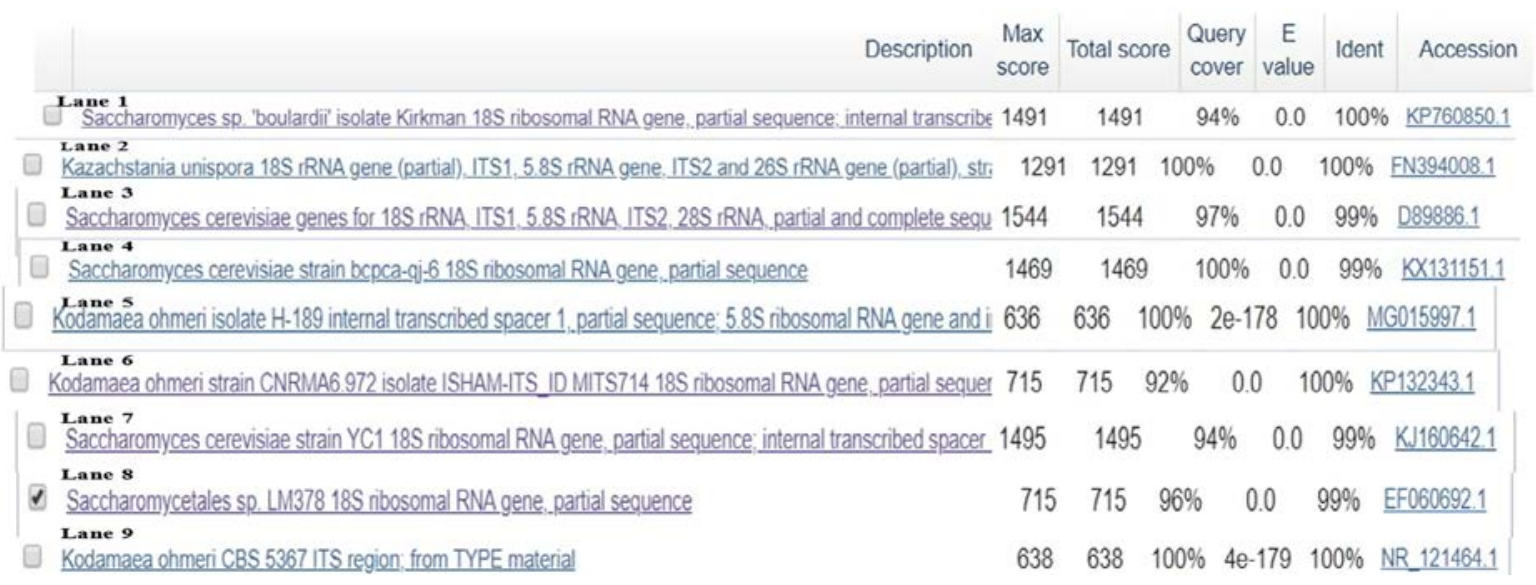

Figure 3. Sequence alignment using BLAST. The highest identity was shown between $99 \%$ and $100 \%$.

TABLE I. GENETIC IDENTIFICATION OF THE SPECIES

\begin{tabular}{ccccc}
\hline $\begin{array}{c}\text { PCR LanePCR } \\
\text { product length } \\
\text { (bp) }\end{array}$ & Yeast species & $\begin{array}{c}\text { Identity } \\
(\%)\end{array}$ & Accession no. \\
\hline 1 & 853 & $\begin{array}{c}\text { Saccharomyces } \\
\text { boulardii }\end{array}$ & 100 & KP760850.1 \\
\hline 2 & 699 & $\begin{array}{c}\text { Kazachstania } \\
\text { unispora }\end{array}$ & 100 & FN394008.1 \\
\hline 3 & 861 & $\begin{array}{c}\text { Saccharomyces } \\
\text { cerevisiae }\end{array}$ & 99 & D89886.1 \\
\hline 4 & 804 & $\begin{array}{c}\text { Saccharomyces } \\
\text { cerevisiae }\end{array}$ & 99 & KX131151.1 \\
\hline 5 & 366 & Kodamaea ohmeri & 100 & MG015997.1 \\
\hline 6 & 420 & Kodamaea ohmeri & 100 & KP132343.1 \\
\hline 7 & 862 & $\begin{array}{c}\text { Saccharomyces } \\
\text { cerevisiae }\end{array}$ & 99 & KJ160642.1 \\
\hline 8 & 405 & Saccharomycetales & 99 & EF060692.1 \\
\hline 9 & 345 & Kodamaea ohmeri & 100 & NR_121464.1 \\
\hline
\end{tabular}

Table I shows the species of probiotic yeast found in the samples of kefir drink from Malaysia along with the accession number obtained from the database. Based on the 16s-rDNA identification, the indigenous yeast isolated were classified into three major cluster which are Kodamaea, Kazachstania and Saccharomyces group respectively. Saccharomyces and Kodamaea were found to be the major population in all the isolated yeast strains.

These results are consistent with a previous research [16] where the most common yeast species that can be found in the microbial mixture in the kefir is Saccharomyces cerevisiae. Another study done from Brazil reported that Saccharomyces, Candida and Kluyveromices are the abundance genera that can be found in the kefir drink in the region [17].

However, the yeast species diversity observed in kefir samples may be influenced by the milk's characteristics 
and the variety of microbial mixture in the samples where it may be different based on the origin of the kefir samples. In this case, the local Malaysian kefir drink samples can be found up to three different types of yeast genera.

\section{CONCLUSION}

In the present study, nine of yeast strains were isolated from the complex microbial consortium of kefir drink. The ITS region of all the isolated strains were successfully amplified by using PCR method and identified by using sequencing analysis. Genus Saccharomyces and Kodamaea were found to be the major population of yeast strains in the kefir drink samples.

Since, indigenous yeast strains from genera Saccharomyces and Kodamaea has been isolated from the local Malaysia kefir drink that regularly consumed by the Malaysian people. Therefore, the potential of probiotic role seem to be quite important for the yeast strains found in the Malaysian kefir drink. The yeast strains found could be used as a new source of probiotic formulation such as in tablet or capsule form or can be incorporate in the supplement or functional food. However, further study to observe the probiotic traits should be carried out to investigate potential of isolated yeast strains.

\section{ACKNOWLEDGMENT}

This study was supported by a grant (RDU180379) from Universiti Malaysia Pahang.

\section{REFERENCES}

[1] M. R. Prado, et al., "Milk kefir: Composition, microbial cultures, biological activities, and related products," Frontiers in Microbiology, vol. 6, p. 1177, 2015.

[2] Z. Chen, J. Shi, X. Yang, B. Nan, Y. Liu, and Z. Wang, "Chemical and physical characteristics and antioxidant activities of the exopolysaccharide produced by Tibetan kefir grains during milk fermentation,” International Dairy Journal, vol. 43, pp. 15-21, Apr. 2015.

[3] E. R. Farnworth, "Kefir: A complex probiotic," Food Science and Technology Bulletin: Functional Foods, vol. 2, pp. 1-17, 2005.

[4] E. Dertli and A. H. Çon, "Microbial diversity of traditional kefir grains and their role on kefir aroma," LWT - Food Science and Technology, vol. 85, pp. 151-157, Nov. 2017.

[5] FAO/WHO, "Eport of a joint FAO/WHO expert consultation on evaluation of health and nutritional properties of probiotics in food including powder milk with live lactic acid bacteria," FAO Food and Nutrition Paper, vol. 85, pp. 1-4, 2001.

[6] I. Hojsak, et al., "Probiotics for the prevention of nosocomial diarrhea in children," Journal of Pediatric Gastroenterology and Nutrition, vol. 35, no. 2, pp. 142-145, 2017.

[7] V. Dubey, A. R. Ghosh, K. Bishayee, and A. R. Khuda-Bukhsh, "Appraisal of the anti-cancer potential of probiotic pediococcus pentosaceus GS4 against colon cancer: In vitro and in vivo approaches," Journal of Functional Foods, vol. 23, pp. 66-79, May 2016.

[8] P. Brun, et al., "Saccharomyces boulardii CNCM I-745 supplementation reduces gastrointestinal dysfunction in an animal model of IBS,” PLOS ONE, vol. 12, no. 7, p. e0181863, Jul. 2017.

[9] S. Eggers, A. Barker, S. Valentine, T. Hess, M. Duster, and N. Safdar, "Impact of probiotics for reducing infections in veterans (IMPROVE): Study protocol for a double-blind, randomized controlled trial to reduce carriage of staphylococcus aureus," Contemporary Clinical Trials, vol. 52, pp. 39-45, 2017.

[10] W. Qamar, M. R. Khan, and A. Arafah, "Optimization of conditions to extract high quality DNA for PCR analysis from whole blood using SDS-proteinase K method," Saudi Journal of Biological Sciences, vol. 24, no. 7, pp. 1465-1469, Nov. 2017.

[11] P. Goldschmidt, S. Degorge, L. Merabet, and C. Chaumeil, "Enzymatic treatment of specimens before DNA extraction directly influences molecular detection of infectious agents,” PLOS ONE, vol. 9, no. 6, p. e94886, Jun. 2014.

[12] T. D. Petes, B. Byers, and W. L. Fangman, "Size and Structure of Yeast Chromosomal DNA (electron microscopy/mitochondrial DNA/linear DNA)," Proceedings of the National Academy of Sciences of the United States of America, vol. 70, no. 11, pp. 3072-3076, 1973.

[13] T. Pham, et al., "Evaluation of ITS PCR and RFLP for differentiation and identification of brewing yeast and brewery 'wild' yeast contaminants," J. Inst. Brew, vol. 117, no. 4, pp. 556568, 2011.

[14] K. J. Martin and P. T. Rygiewicz, "Fungal-specific PCR primers developed for analysis of the ITS region of environmental DNA extracts,” BMC Microbiology, vol. 5, p. 28, May 2005.

[15] A. J. Buehler, R. L. Evanowski, N. H. Martin, K. J. Boor, and M. Wiedmann, "Internal Transcribed Spacer (ITS) sequencing reveals considerable fungal diversity in dairy products," Journal of Dairy Science, vol. 100, no. 11, pp. 8814-8825, Nov. 2017.

[16] D. Cassanego, et al., "Identification by PCR and evaluation of probiotic potential in yeast strains found in kefir samples in the city of Santa Maria, RS, Brazil,” Food Science and Technology, vol. 38, no. 1, pp. 59-65, Oct. 2017.

[17] R. S. O. Bergmann, M. A. Pereira, S. M. O. M. Veiga, J. M. Schneedorf, N. M. S. Oliveira, and S. E. Fiorini, "Microbial profile of a kefir sample preparations: Grains in natura and lyophilized and fermented suspension,” Ciência e Tecnologia de Alimentos, vol. 30, no. 4, pp. 1022-1026, 2010.

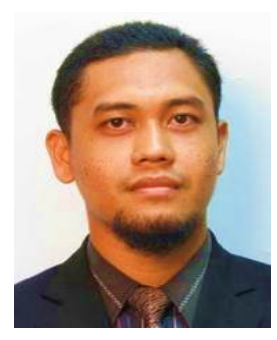

Mohd Akmal Azhar was graduated from Universiti Teknologi Malaysia in 2006. His main area of research interest are biotechnology and nutraceutical. $\mathrm{He}$ is currently a PhD student at Universiti Malaysia Pahang, Malaysia.

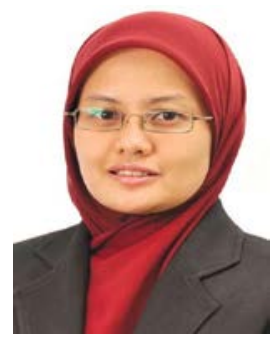

Mimi Sakinah Abdul Munaim was grauated from Universiti Teknologi Malaysia in 2000. Her main area of research interest are separation, enzyme and pharmaceutical technology. She is currently a deputy dean of institute of postgrauate study at Universiti MalaysiaPahang. 